\title{
Decomposing the Social Mobility in China: From 1989 to 2015
}

\author{
Kaiyi Wen ${ }^{1}$ \\ Preliminary. Please do not circulate. Comments are mostly welcome.
}

\begin{abstract}
This research focuses on the changes of social mobility and its driving factors in China from 1989 to 2015. I use the China Health and Nutrition Survey (CHNS) panel data which tracks the individuals across survey years so that I can observe and analyze the social mobility changes at the individual-level across years. I find decreasing social mobility in China from 1989 to 2006 and it fluctuates after that. I also find the industry factor plays more significant roles in the changes of social mobility in China as time progresses toward the present. This is mainly due to more people working in the first industry transferring to the second or the third industry. Although more people transfer to the industries with higher income premiums, the general social mobility in China is decreasing. One possible explanation to the contradiction may be the increasing income premiums across industries. I also use the JMP Decomposition to quantify and corroborate my results.
\end{abstract}

Keywords - China; Decomposition; Industry; Inequality; Social Mobility

\section{Introduction}

Although the economy of China has developed with a high speed in recent decades, the income inequality in China has increased simultaneously. For example, Xie and Zhou (2014) suggest that China's income inequality since 2005 has reached very high levels, with the Gini coefficient in the range of $0.53-0.55$.

The problem of inequality is highly related to the changes in social mobility. It is widely believed that countries with greater income inequality also have lower intergenerational mobility. This relationship, known as the Great Gatsby Curve (GGC), has been prominently cited by many researchers (Jerrim and Macmillan, 2015). Moreover, if the social mobility is limited in a country, the inequality will bring more serious problems because of the solidification of classes. Zhou and Xie (2017) find that the social fluidity in China is high by international standards, which also means the limited social mobility in China. Therefore, I want to investigate how social mobility changed in China from 1989 to 2015 and understand the driving factors of social mobility in recent decades.

\footnotetext{
${ }^{1}$ Boston University, Department of Economics. email: wenk@bu.edu
} 
To investigate the social mobility in China, I use the China Health and Nutrition Survey (CHNS) data. The most desirable characteristic of the data is that it is panel data that can be dated from 1989. It is the only available panel data in China which can give the relative information of the observations during such a long time period. It offers the chance to track the individuals in multiple years.

Therefore, the nature of the panel data allows for the calculation of the social mobility changes in China from 1989 to 2015 . The economic situation during the 26 years was complicated in China. It began with rapid growth during this period but the inflation was also accelerating (Brandt and Zhu, 2000). According to the data from World Bank, the GDP per capita (constant 2010 USD) increased from 712.115 to 6484.436 from 1989 to 2015 and the average inflation rate was $5.513 \%$ during this time period.

Accompanied with the rapid growth of economy in China during this time span, the inequality problem also increased. The Gini indexes of 1990 to 2015 changed from 0.322 to 0.386 and reached the peak of 0.437 in 2010 .

In order to quantify and calculate the social mobility, I categorize the observations into three classes of people which are the poor, the middle class, and the rich based on their incomes and the corresponding rankings of their incomes for each survey year. I define the social mobility by the probability of promoting from the poor class in the last wave of the survey year to the rich class in the current survey year for the observations. In addition, I also use the proportion of the poor in the last wave of the survey year remaining in the poor class in the current survey year to measure the social mobility changes. The first measurement is positively related to the social mobility and the second measurement is negatively related to the social mobility. In general, the social mobility in China gets more limited from 1989 to 2006 and fluctuates after that.

To take a further look at how large of a role the industry factor plays in the changes of social mobility, I calculate the observations' counterfactual incomes and corresponding relative rankings by assuming the observations remain in the same industries as that in their last survey years. I find the social mobility gap between the calculation with real incomes and the calculation with counterfactual incomes gets larger as time progresses toward the present. It means the industry factor plays an increasing role in the changes of social mobility.

In order to understand how the industry factor plays more significant roles in explaining the social mobility, I investigate the mobility across industries. I obtain the results of the changes across the first, the second, and the third industries. I find the industry net change ratio of the first to the second industry increases consistently as time progresses toward the present, the industry net change 
ratios of the first to the third industry and second to the third industry are always positive but fluctuate between time periods. The increasing industry mobility fits with the situation that the industry factor plays more important roles in explaining the social mobility as time progresses toward the present.

There is a paradox that the industry mobility increases in the recent time period but the general social mobility decreases. One possible reason could be the returns to work at the second and the third industry increase sharply compared to work at the first industry as time progresses toward the present. Another potential explanation is the much more limited social mobility within industries, which results from the increasing income premiums across industries.

To further corroborate my potential explanations and quantify my reasoning about the relative importance of income premiums and industry compositions, I use the Juhn, Murphy and Pierce (JMP) Decomposition to help me perceive the weights of different factors. JMP offers a way for describing the components of income or wage changes that could be attributed to measured prices, measured quantities and residuals.

On one hand, I find the price effect plays the major role in explaining the income premiums between the first and the second industry. As for the relative income differences between the second and the third industry, the price effect plays almost all the roles in explaining the total income differences from 1989 to 1997. The findings with the JMP Decomposition corroborate my reasoning that the income premiums across industries explain a lot in the more limited social mobility within industries.

On the other hand, the quantity effect increases sharply from 1997 to 2004 which fits with the changes of industry net change ratios during the same time period. More people make forward industry changes during this time period and it contributes much to the changes of social mobility. ${ }^{2}$ Meanwhile, the price effect decreases dramatically in this time period. After 2004, the two effects have similar and consistent weights in explaining the total income differences between the second and the third industry.

Although foregoing researchers have payed some attention to the income inequality problem in China, most of them focus on the regional income inequality and ruralurban inequality. Such as Chen and Fleisher (1996) project that overall regional inequality is likely to decline modestly but the coast/noncoast income differential is likely to increase. Kanbur and Zhang (1999) find that the

\footnotetext{
${ }^{2}$ Forward industry changes mean the change from the first to the second industry or the change from the second to the third industry.
} 
contribution of ruralurban inequality is much higher than that of inland-coastal inequality. Sicular et al. (2007) point out the location of residence remains the most important factor underlying the urbanrural income gap meanwhile Xie and Zhou (2014) indicate that a substantial part of China's high income inequality is due to regional disparities and the rural-urban gap.

The problem of social mobility which is highly related to the income inequality has received much attention from researchers but the research about the general social mobility in China from 1989 to 2015 are limited. Wu and Treiman (2004) focus on the time span from 1955 to 1996 to investigate the effects of household registration system (hukou) on social mobility. They find transforming one's hukou status from rural to urban is a central aspect of upward mobility. Nee (1996) pays attention to the mobility problem in China during the early 1990s, he finds that China has undergone rapid and extensive household income mobility, incrementally altering the stratification order based on socialist redistribution. He focuses on the regional mobility variations at the household-level. Bian (2002) realizes Chinese class stratification has transformed from a rigid status hierarchy under Mao to an open, evolving class system in the post-Mao period, but his work is based on synthesizing the research achievements from 1980s to 1990s without real data renewed to analyze.

Different from previous research, I focus on the social mobility changes in the recent time period by analyzing the latest data. I also take a further look at the driving factors of the social mobility which differentiates this research from the aforementioned social mobility research.

Moreover, none of the researches aforementioned use the data at the individual-level nor pay attention to the current time period. The paper closest to my research is the work of Chen and Cowell (2017). They focus more on the changes from the decade immediately preceding the millennium to the decade immediately following. The increment they selected as a criterion is much longer than that in my research (each survey year). Therefore, I can perceive more frequent social mobility changes with a shorter increment chosen.

More importantly, I focus on the driving factors of the changes in social mobility and I investigate how the driving factors play the roles in the social mobility in China which are absent in the work of Chen and Cowell (2017). In this paper, I focus on the general social mobility during the survey span and its driving factors especially for the industry changes which distinguishes my research from their research.

In sum, my paper makes contributions to the analysis of social mobility in China in the following ways. Firstly, I focus on what the industry factor contributes to the changes of social mobility in my research that fills up the void in the field about industry transform effects on social mobility. I also use the JMP Decomposition to analyze the components of the income differences across industries 
with innovation. The trends of the component factors will be an interesting discussion that few research has covered before.

Beyond that, I select the latest data from 1989 to 2015, which represents a long enough time span to help me ascertain the mobility changes during the current time period. Moreover, the data I use is at an individual-level which gives me the chance to make counterfactual and decomposition analysis for the individuals. While the foregoing research about social mobility in China often uses the data at household-, county-, province-level, the data I use at the individual-level helps me to be specific in explaining the general changes in social mobility across years.

The paper will be organized as follows. Section 1 will make a general demonstration of the results I find and the structure of the paper. Section 2 will focus on the description of my data source and make some summaries of the major variables. Section 3 includes the main results, I analyze the social mobility with income positions and explain the important industry factor in this part. In section 4, I discuss the JMP Decomposition to have a closer look at how industry factor contributes to the changes of social mobility and I make the conclusions in the last section.

\section{Data Description}

\section{a. Data Source}

The data I use comes from The China Health and Nutrition Survey (CHNS), which is an ongoing international project collaboratively done by the University of North Carolina at Chapel Hill and the National Institute for Nutrition and Health (NINH, former National Institute of Nutrition and Food Safety) at the Chinese Center for Disease Control and Prevention (CCDC).

The most desirable characteristic of this panel data is that it is able to track the same individuals in different years then I can analyze the changes of the targeted individuals during the survey years. The data from CHNS includes widespread demographic information. The survey of the data took place over a 7-day period using a multistage, random cluster process to draw a sample of about 7,200 households with over 30,000 individuals in 15 provinces and municipal cities that vary substantially in geography, economic development, public resources, and health indicators. I focus on the adult individuals with positive incomes as the analyzed sample. To be more specific, whose identities are students, retired people and the ones who report non-positive individual incomes are not included in the sample chosen.

\section{b. Summaries of Variables}

I transfer the original data to a more desirable format. I use the deflation indexes which treat 2015 as the base year to transfer the individual incomes to the format in real terms. I limit the extreme 
values in the data to reduce the effect of possibly spurious outliers. Furthermore, I generate several percentage indexes by different categorizing rules such as within cohort groups, total individuals, urban or rural groups, industry groups and province groups. I categorize people equally into three classes which are the poor, the middle class, and the rich based on their relative position under different percentage indexes.

I also delete the observations who come from Beijing, Shanghai and Chongqing in the foregoing sample. The reason is that these three regions are added since 2011 and they are all municipalities in China. The political and economic specialities of them will disrupt the comparability of social mobility across years in the sample.

The most crucial variable in this research is individual income. Intuitionally, the means of individual incomes should increase with years. As we can see in Table 1 which reports the individual incomes after 1 percentage winsorisation, ${ }^{3}$ in general, the means of individual incomes increase sharply during the survey years except at year 1991, especially for the recent 10 years which fits with my intuition. The income gaps between individuals also increase sharply which can be observed from the increasing standard deviations of individual incomes in Table $1 .{ }^{4}$

Industry information is also one of the most significant factors in this research. I categorize people into three industries which are the first, second, and third industries based on their major occupations for each survey year. I want to investigate the change of distributions in three industries within survey years.

As we can see in Table 2, in general, less people choose to stay in the first industry as time progresses toward the present and more people prefer to work in the second or the third industry. The finding fits with the intuition because of the increasing productivity in the first industry and the upward demand of labor in the second and third industries. The general summary of other less important variables within total individuals across all survey years are reported in Table A1.

My research is based on a long-term survey sample. The average survey years of different individuals is near to 9 years and about 7.5 percentage individuals complete the surveys of all the survey years.

\footnotetext{
${ }^{3}$ Winsorization is a way to minimize the influence of outliers in the data by either assigning the outlier a lower weight or changing the value so that it is close to other values in the set.

${ }^{4} \mathrm{I}$ also get similar results by using the income data without winsorisation (Table A2) and with 5 percentage winsorisation (Table $A 3$ ) respectively.
} 
I also pay attention to the traceable condition between each two survey years to check how many individuals had been surveyed in each year can be remained in next survey year. ${ }^{56}$

\section{c. Data Shortcoming}

The characteristic of being able to be tracked for the same individuals in multiple years is a desirable and attractive point of the data used in this research, but there are still some untraceable observers. For instance, an individual who changed a city to begin his new work in another province or an individual who moved to urban areas from rural areas may lack the report of his information in next survey year at where he was surveyed. The data in this research cannot include enough information which shows the labor migration between provinces or between urban and rural areas.

\section{Social Mobility Analysis with Income Positions}

\section{a. Income Position Methodology}

\section{i. Real Income Positions}

Observing the changes of observations' positions across classes is my major way to explain the social mobility. I rank the incomes of all the observations to generate their income positions. I categorize the observations into three classes of people equally which are the poor, the middle class, and the rich based on their positions under different ways of grouping the observations.

The poor are the observations range from the lowest income position to the first one third position among the observations. The observations range from the first one third position to the second one third position among the observations are regarded as the middle class. The left observations who range from the second one third position to the highest income position are regarded as the rich.

The main ways of categorizing the observations include by cohorts, ${ }^{7}$ by industries and by regarding all the observations as the whole pool. Under each circumstance of categorizing the observations, I generate their class positions for each survey year.

\footnotetext{
${ }^{5}$ In this part, the counting is based on the raw data from CHNS before my own sample selection.

${ }^{6}$ In general, the weights of last survey years are decreasing as more provinces are included into the sample in later survey years and this part of new samples will not show up in last survey years. The result is shown in Table 3.

${ }^{7}$ I regard 10 years as a cohort to group the observations in this research.
} 
I sum the changes of the observations' class positions from the last survey year of the targeted survey year to the targeted survey year. I focus on the changes of the poor to stay at the poor class and the changes of the poor to be the rich to explain the changes of social mobility.

I generate the percentages of the poor from the last survey year for each survey year to remain in the poor class in each survey year under the three ways of grouping the observations. I use figures to show the tendencies of the poor from last survey year for each survey year to remain in the poor class in each survey year.

Similarly, I generate the percentages of the poor from the last survey year of each survey year to be the rich in each survey year. The tendencies of the poor to be the rich under three grouping ways are also shown in my figures.

\section{ii. Counterfactual Income Positions}

To have a better understanding of the effects of industry changes on social mobility, I calculate the counterfactual incomes for the observations if they do not change their industries. The mincer-type regression ran for each survey year is shown as follows:

$$
Y_{i t}=\beta_{1} \operatorname{Sec} \operatorname{In}+\beta_{2} \operatorname{ThIn}+X_{i t} \theta_{i t}+\gamma_{p}+{ }_{i t}
$$

The dependent variable means the observation's incomes in the $t$ survey years. SecIN and ThIN are the dummy variables which indicate the observations who work in the second or the third industry. $X_{i t}$ is the vector of the controlled demographic variables $\theta_{i t}$, which includes female, year of education, dummy variables Han ethnicity and urban areas. $\gamma_{p}$ indicates the region factor (provinces) of the observations which shows the fixed effects of the observations' incomes.

I make adjustments to the observations' real incomes in each survey year by adding or subtracting the relative incomes brought by the changes of their industries to make a new rank assuming no observations change their industries. ${ }^{8}$

I generate the new positions for all the observations under three grouping ways with their counterfactual incomes. Furthermore, I observe the tendencies of the poor to remain in the poor class and tendencies of the poor to be the rich with their counterfactual income positions in the same way I use in the last part.

\footnotetext{
${ }^{8}$ For instance, if one observation was in the first industry in 1989 and changed his industry to the second industry in 1991, I will subtract the value of $B_{1}$ in the mincer-type regression of 1991 from the observation's real incomes in 1991 to generate his counterfactual incomes.
} 
In this case, I focus on two grouping ways which are grouping within industries and grouping within all the observations. I show the comparisons of the tendencies of the poor to be the rich and the poor to remain in the poor class with the original income positions and the counterfactual income positions in two grouping ways, respectively.

\section{iii. Industry Factor}

I choose the industry factor to generate counterfactual incomes because I find its importance and rich effects on income positions with the foregoing analysis. I infer both the changes of industry mobility and the changes of individuals' relative incomes brought by the changes of the industries the observations work in will contribute much to the changes of the observations' positions under different categorizing rules.

I observe the changes of industry mobility by summing the observations who are at a targeted industry for the targeted survey years if the same observations are in another industry at the last survey years of the targeted survey years.

I get the percentages of the observations who change their industries for all survey years. I also get the results of three kinds of forward changes of industry mobility by observing each kind of forward change between industries. ${ }^{9}$ Similarly, I get the results of three kinds of backward changes of industry mobility.

I count the net changes in the numbers of observations who change their industries by combining up the forward changes with backward changes across industries. I show the percentages of the observations' net changes across industries for all survey years. I get the tendencies of three kinds of industry net changes by summing up each kind of net changes between industries.

I get the changes of the observations' relative incomes by regressing the observations' real incomes on many demographic factors including their industry factors for all survey years. The regression is the same as equation (1) which I have shown. ${ }^{10}$

\footnotetext{
${ }^{9}$ Forward changes mean moving from the first industry to the second or the third industry or moving from the second industry to the third industry.

${ }^{10}$ The explanation of the regression in this part is the same as the counterfactual regression in the last part.
} 
I take the observations in the first industry as the base group and the positive coefficients of the industry dummy variables $\left(\beta_{1} \& \beta_{2}\right)$ represent the relative more incomes of working in the second or the third industry with respect to working in the first industry.

I also get the relative incomes of working in the third industry with respect to working in the second industry by making the difference of the two relative incomes I mention with respect to working in the first industry $\left(\beta_{2}-\beta_{1}\right)$.

I get the values of relative incomes across industries for all survey years. I also get the tendencies of the changes of the relative incomes across industries by observing the income changes in each kind of industry mobility.

Similarly, I regress the observations' real incomes in percentage terms as follows.

$$
\ln Y_{i t}=\beta_{1} \operatorname{Sec} \operatorname{In}+\beta_{2} \operatorname{ThIn}+X_{i t} \theta_{i t}+\gamma_{p}+{ }_{i t}
$$

I keep doing all the other operations I mention for the regression of generating the counterfactual incomes to get the figure which shows the trends of relative incomes across industries for all survey years in percentage terms.

\section{b. Income Position Analysis Results}

In this part, I will firstly make sure the sample is valid and reasonable by observing the correlation of observations' cohort positions across the survey years. I also regress the observations' cohort positions on some demographic factors such as gender, education, region (province) and industry. Furthermore, I will explain the changes of social mobility with a comparison by observing the changes of observations' cohort positions with or without industry counterfactual incomes. I will also demonstrate and explain the industry factor about its own industry mobility and its effects on the changes of relative incomes after the anaylsis of the comparison.

\section{i. General Validness Check}

To make sure the sample is reasonable and objective, I regress the observations' cohort positions in targeted survey years on their cohort positions in foregoing survey years. I focus on the effects of the observations' cohort positions in foregoing survey years on their cohort positions in the targeted survey years. 
I expect the correlations between the observations' current cohort positions and their past cohort positions in foregoing survey years will increase as time progresses toward the present. I get the results of effects on cohort positions in targeted survey years from the cohort positions of foregoing three survey years in Table 4. In general, the results fit with my idea. ${ }^{11}$

I also pay attention to the correlation among the observations' cohort positions across all survey years. As we can see in Table A5, the correlations between the observations' current cohort positions and their historical cohort positions strictly increase as time progresses toward the present which fits with the intuition. ${ }^{12}$

After observing the correlation of observations' cohort positions across years, I focus on the factors which contribute to the composition of observations' cohort positions within each survey year to ensure the sample is reasonable and valid in another perspective.

I regress observations' cohort positions within each survey year on demographic factors. As we can see in Table A4, education is positively related to the change of cohort positions, the return to education also increases with years which fits with the intuition and foregoing research. Zhang et al. (2005) have pointed out a dramatic increase in the returns to education in China, from only 4.0 percent per year of schooling in 1988 to 10.2 percent in 2001. Most of the rise in the returns to education occurred after 1992 and reflected an increase in the wage premium for higher education.

Female receive a relatively disadvantageous effect among cohort groups, the negative effect on female also increases with years in general. The region factor plays an important role in explaining the cohort positions. The regions with better economic conditions such as Shanghai, Jiangsu often contribute more to cohort positions which means the observations in these regions are more likely to have higher cohort positions.

However, the general effect level of region factor decreases with years. A possible reasoning is that the regions with relatively poor economic conditions are catching up with the relatively rich regions because of the marginal dimishing growth in economy in general.

My reasoning fits with what Fan and Sun (2008) have demonstrated in their study. They point out that interprovincial inequality declined during the 1980s, increased in the 1990s, was relatively stable

\footnotetext{
${ }^{11}$ I got the similar results when I observed the effects of cohort positions of foregoing 2 survey years as Table $\mathrm{A} 7$ shows.

${ }^{12}$ I got the similar results by checking correlations of positions within all observations, the result is shown in Table A6.
} 
from the late 1990s to 2004, and has declined thereafter. Since 2004, however, the study reveals that both interregional and intraregional inequalities have declined, reflecting convergence in growth rates among provinces and among regions in China.

About $80 \%$ of the variations of the observations' cohort positions can be explained by the independent variables jointly which also elucidates the sample is valid.

\section{ii. $\quad$ Real Income Position Changes}

Observing the changes of the observations' cohort positions is one of my major ways to explain the changes of social mobility. I focus on the changes of the observations' positions among three classes I categorize to explain the social mobility during the survey years. In Figure 1, all the three lines are upward in general. It means the tendency of the poor to remain in the poor class is increasing with years.

The percentages of the poor who remain in the poor class are obviously less when I calculate the positions of observations within each industry group. That is to say, the social mobility is much greater when I sort people by three industries and people are more likely to change their classes in this case.

However, when I sort the observations by three industries, I find the tendency of the poor to remain in the poor class decreases from 1989 to 1997. This obvious downward tendency in this time period is different from the general upward tendency within each industry group in other time period. It is also different from the general upward tendency when I sort the observations by cohort groups or within all the observations.

I get a similar result by observing the change from the poor to the rich. In Figure 2, all the three lines are downward in general which means the tendency of the poor to become the rich is decreasing with years in general.

Similar as my finding in Figure 1, the change of the observations' positions from the poor to the rich increases from 1989 to 1997 and even the upward tendency do not stop until 2000 when I sort the observations by three industries.

It shows different tendency from the general downward tendency within each industry group in other time periods. It is also different from the generally downward tendency when I sort the observations by cohort groups or within all the observations. The probability of becoming the rich 
as the poor is also much higher when I sort people by three industries. The ideas fit with the results in Figure 1.

I can conclude that although the social mobility increases across industries from 1989 to 2000, the general social mobility across all the observations decreases in this time period. It also means the social mobility within industries decreases much more which makes the progress of social mobility across industries not obvious and significant enough to affect the general trend of less social mobility.

When I consider all the observations together, the social mobility is the least. The percentages of the poor to remain in the poor class are the highest compared with the other two tendencies with different class division rules. The percentage of the poor to become the rich is the lowest. It fits with my intuition because I give the most general condition in this case.

Interestingly, a clear and strong wave occurs during the same period in both Figure

1 and Figure 2. From 2006 to 2009, the originally upward tendency of the poor to remain in the poor drops unconventionally and it increases sharply from 2009 to

2011. The inverse situation also occurs when I observe the tendency of the poor who become the rich.

A possible explanation is that the worldwide financial crisis in 2008 brings China some new opportunities for people to change their classes. As Wisman (2013) mentions in his study, new consumption externalities because of the financial crisis were generated, forcing households to struggle harder to maintain the welfare of their families and their relative social status. I infer the similar situation may also occur in China during the crisis period. The social mobility goes back the original level after the shock of the event.

\section{iii. Counterfactual Income Position Changes}

I also observe the changes among three classes with the observations' counterfactual incomes. As Figure 3 shows, the percentages of the poor to become the rich within industry groups become lower after controlling industry information in all survey years. In other words, if I assume the observed poor do not change the industries they work in, they will have less chances to become the rich.

More importantly, when I categorize the observations by industries, I find the gap between the proportions of the poor to be the rich calculated with real incomes and that calculated with counterfactual incomes gets larger as time progresses toward the present. It means the industry 
factor plays increasing roles in explaining the social mobility from the poor to the rich as time progresses toward the present.

In addition, the tendency of the changes dealing with the counterfactual incomes follows with the tendency of the changes dealing with the real incomes closely within industry groups. It means the control of industry information within industry groups plays an important role in explaining the general decreasing social mobility with controlled industry factor. ${ }^{13}$

I get the similar results by observing the changes of the poor to remain in the poor class. As Figure 4 shows, the changes of the observations' positions within industry groups for the poor to remain in the poor class become higher when I use the observations' counterfactual incomes to analyze the changes of the income positions.

The tendency is also increasing with years in general and shows unconventional downward direction from 1989 to 1997, which fits with the foregoing results. The gap between the proportions of the poor to remain in the poor class calculated with real incomes and that calculated with counterfactual incomes also gets larger as time progresses toward the present in general. The findings fit with the foregoing results. ${ }^{14}$ I can conclude that the general social mobility becomes more limited when I control the industry factor and the industry factor explains more in the changes of social mobility as time progresses toward the present based on the foregoing analysis.

\section{iv. Industry Changes}

I choose industry information to be the controlled factor because industry information is a significant factor in this research. The industry mobility and its effect on relative income premiums are the two major reasons I believe that contribute to the different situations about social mobility after controlling the industry factor.

In general, less people choose to remain in the first industry and change to work at the second or the third industry as Figure 5 shows. The tendency is increasing with years. It fits with the intuition

\footnotetext{
${ }^{13}$ It fits with the intuition that the industry control within all observations in the sample works not so well since I give a more general condition in this case. Whereas, the tendency of the poor to become the rich is decreasing in general which is the same as the forgoing results.

14 The similar but not so robust results can be observed by controlling industry information within all observations in the sample. The other two lines on the top of Figure 4 show the ideas.
} 
because of the increasing productivity in the first industry with the development of modern agricultural technology and more attractive incomes in the second and the third industry.

As we can see in Figure 7, the relative income growth for the observations who transfer to the second or the third industry from the first industry are increasing sharply with years. ${ }^{15}$ I infer the increasing income premiums across industries also contribute to the more limited social mobility within industries and then make up the general decreasing social mobility.

The weights of changing to the second or the third industry from the first industry are similar. Whereas, the weights of changing to the third industry from the second industry are much higher in all survey years. The reason is that the first industry usually means relatively low incomes intuitionally, so the people who are unsatisfied with their incomes in the second industry will always change to work in the third industry. ${ }^{16}$

In general, I observe the industry net change ratio is close to zero at the beginning of the survey time period. It explains why the social mobility results observed with the counterfactual incomes are similar with that observed with real incomes at the beginning of the survey period. As time progresses toward the present, more people change their industries as Figure 6 shows. It also makes the industry factor explain more in the social mobility gap between the calculation with real incomes and the calculation with counterfactual incomes as time progresses toward the present.

\section{JMP Decomposition Discussion}

\section{a. JMP Decomposition Methodology}

\section{i. Introduction to JMP Decomposition}

Juhn, Murphy and Pierce (1993) set out their highly cited paper to summarize the rising dispersion of earnings in the U.S. during the 1970s and 1980s. JMP offered a wonderful tool for describing the components of wage density changes that could be attributed to measured prices, measured quantities and residuals (which they referred to as unmeasured prices and quantities).

\footnotetext{
${ }^{15}$ I get the similar results when I observe the relative income changes in percentage terms as Figure 8 shows.

${ }^{16}$ Figure 6 shows the industry net change ratios. I can see the changes from the second to the third industry are often with relatively big numbers among the three kinds of industry changes in the survey years which fits with the results in Figure 5.
} 
As I mentioned, the industry factor plays a significant role in explaining the changes of the observations' income positions. I want to investigate the components of the income changes within the industry factor, so I choose this tool to help me have a closer look at the distribution of different effect factors in industries.

\section{ii. JMP Decomposition Analysis}

In general, the wage or income equation in time $t$ can be written as,

$$
Y i t=X i t \beta t+u i t
$$

Write $u_{i t}$ as,

$$
u i t=F-1(\theta i t \mid X i t)
$$

where $F^{-1}\left(\cdot \mid X_{i t}\right)$ is the inverse cumulative distribution of wage or income residuals conditional on $X_{i t}$, and $\theta_{i t}$ is $i$ 's percentile rank in the residual distribution. ${ }^{17}$

I perform the JMP Decomposition with the following three steps. Firstly, to obtain the effect of quantities only, I predict incomes for all the observations in the sample for each survey year using the average coefficient vector $\beta^{-}$, and computing a residual for each observation based on his rank in the targeted survey year's residual income distribution. I then apply the average cumulative residual distribution over the full sample.

Secondly, I would like to get the marginal effect of quantities which JMP called the price effect. I repeat the procedure in last step, now using the coefficient vector $\beta_{t}$ but retaining the average residual distribution.

Finally, the residual effect is simply calculated as the difference between the actual income distribution in the targeted survey year (step 1) and the counterfactual income distribution (step 2).

I get the weights of contributions of differences in quantities, prices and unobservable quantities and prices to the total income differences by performing the JMP Decomposition by steps mentioned for two kinds of forward industry mobility (First to Second Industry \& Second to Third Industry) for each survey year.

I focus on the trends of quantity effects and price effects across years by observing the changes of their weights in explaining the total differences. I get the figures to show the trends of the weights

${ }^{17}$ We need to know that both $\vartheta_{i t}$ and $F\left(\cdot \mid X_{i t}\right)$ will depend on the conditioning variabls $X$. 
by linking the weight distribution points for each survey year within each kind of forward industry mobility.

\section{b. Industry Analysis Results}

\section{i. $\quad$ First to Second Industry Decomposition}

I focus on the changes of components in the relative incomes from the first to the second industry in this part. As Figure 9 shows, in general, the quantity effects play a relatively less significant role in explaining the total income differences between the first and the second industry while the price effects play the major role in explaining the total income differences.

In general, the quantity effects play less important roles as time progresses toward the present form 1989 to 2000 and it begins to contribute more to the total differences from 2000 to 2009. When the quantity effect reaches the peak in 2009, it begins to drop again.

Similarly, I find the symmetric situation when I observe the changes of price effects. The price effects play more crucial roles as time progresses toward the present form 1989 to 2000. Its major roles begin to decrease from 2000 until 2009. What price effects contribute to the total income differences increase again since 2009.

I infer one possible reason which makes up the trend is the relative huge income gap between the first and the second industry. The relative income premiums brought by changing from the first to the second industry are plentiful, it explains why price effect plays much more important role in explaining the total income differences. The aforementioned findings of the trends of industry net change ratio and the relative income changes from the first to the second industry corroborate my reasonings in this part.

\section{ii. $\quad$ Second to Third Industry Decomposition}

I also pay attention to the changes of components in the relative income premiums from the second to the third industry. As Figure 10 shows, the quantity effect plays less roles as time progresses toward the present from 1989 to 1997, and its effect increases dramatically from 1997 to 2004. From 2004 to 2015, the quantity effect falls with fluctuations in general.

The similar but opposite story also happens when I observe the changes of price effects. From 1989 to 1997 , the price effect almost plays all the roles in explaining the total income differences between 
the second and the third industry and its effect also increases with years. Its major effect begins to drop sharply since 1997 until 2004 and it recovers with fluctuations from 2004 to 2015.

I conclude that the price effect plays almost all the roles in explaining the total income differences between the second and the third industry while quantity effect plays almost no roles in that from 1989 to 1997 . The quantity effect increases sharply from 1997 to 2004, meanwhile, the price effect decreases dramatically in this time period. After 2004, the two effects have similar and consistent weights in explaining the total income differences between the second and the third industry.

\section{Conclusion}

In conclusion, I use the latest CHNS data which helps to track the individual observations across the multiple survey years. I observe their changes of social economic positions during the survey years to analyze the changes of social mobility in China during this time span.

I find that the social mobility in China gets more limited from 1989 to 2006 and fluctuates after that. And also, the social mobility gap between the calculation with real incomes and the calculation with counterfactual incomes gets larger as time progresses toward the present. It means the industry factor plays more important roles in explaining the social mobility as time progresses toward the present.

I also pay attention to the industry factor which is the factor I control to do the counterfactual analysis. I find the industry net change ratio of the first to the second industry increases consistently as time progresses toward the present, the industry net change ratios of the first to the third industry and the second to the third industry are always positive but fluctuate between time periods. This is mainly due to the relative income premiums for the observations who change to the second or the third industry from the first industry are increasing sharply as time progresses toward the present. I decompose the industry factor and find the effect levels of price effect and quantity effect also fluctuate between time periods.

I make contributions to the field of social mobility in China by adding the mobility analysis of the latest time span, focusing on the mobility changes at individual-level and paying more attention to the effects of industry factor on social mobility. Although there are still some shortcomings of the data I use and the analysis progress I take, I hope the future studies could make more contributions to the field of social mobility in China based on my research. 


\section{icalingme}

$2^{\text {nd }}$ International Conference on Advanced Research in

MUNICH, GERMANY

BUSINESS, MANAGEMENT \& ECONOMICS

6 - 8 DECEMBER, 2019

\section{Main Tables}

Table 1: Income Summary with 1 Percentage Winsorisation

\begin{tabular}{cccccc}
\hline Year & Mean & Std. Dev. & Min. & Max. & $\mathrm{N}$ \\
\hline 1989 & 4616.66 & 4436.33 & 107.32 & 27148.94 & 8099 \\
1991 & 4287.24 & 3590.57 & 130.83 & 20933.26 & 8047 \\
1993 & 5002.20 & 4758.00 & 76.34 & 27481.20 & 7310 \\
1997 & 7321.35 & 6370.72 & 212.24 & 34537.30 & 7538 \\
2000 & 8966.00 & 8054.45 & 158.28 & 45680.38 & 7662 \\
2004 & 10869.77 & 10341.91 & 138.71 & 55561.52 & 5139 \\
2006 & 13769.15 & 13876.79 & 197.63 & 83850.24 & 4938 \\
2009 & 19401.13 & 20666.12 & 384.13 & 146155.34 & 5349 \\
2011 & 25847.74 & 25776.26 & 527.20 & 169122.94 & 6906 \\
2015 & 41190.66 & 48861.52 & 700.00 & 360000.00 & 5720 \\
\hline
\end{tabular}

Table 2: Distribution in Three Industries

\begin{tabular}{ccccc}
\hline Year & First Industry & Second Industry & Third Industry & N \\
\hline 1989 & 0.52 & 0.30 & 0.17 & 8099 \\
1991 & 0.56 & 0.25 & 0.18 & 8047 \\
1993 & 0.55 & 0.26 & 0.18 & 7310 \\
1997 & 0.54 & 0.23 & 0.22 & 7538 \\
2000 & 0.52 & 0.24 & 0.23 & 7662 \\
2004 & 0.44 & 0.23 & 0.25 & 5139 \\
2006 & 0.46 & 0.26 & 0.28 & 4938 \\
2009 & 0.45 & 0.25 & 0.29 & 5349 \\
2011 & 0.34 & 0.28 & 0.37 & 6906 \\
2015 & 0.21 & 0.36 & 0.43 & 5720 \\
\hline
\end{tabular}




\section{icalingme}

$2^{\text {nd }}$ International Conference on Advanced Research in MUNICH, GERMANY BUSINESS, MANAGEMENT \& ECONOMICS

Table 3: Tracks between Waves

\begin{tabular}{cccc}
\hline Year & N(Last Wave $)$ & N(The Wave) & Weights of N(Last Wave) \\
\hline 1991 & 7765 & 9219 & 0.84 \\
1993 & 7408 & 8625 & 0.86 \\
1997 & 5378 & 8965 & 0.60 \\
2000 & 6431 & 9365 & 0.69 \\
2004 & 5442 & 7470 & 0.73 \\
2006 & 4945 & 7123 & 0.69 \\
2009 & 4549 & 7548 & 0.60 \\
2011 & 5214 & 10021 & 0.52 \\
2015 & 5868 & 10373 & 0.57 \\
\hline
\end{tabular}




\section{icalinme}

$2^{\text {nd }}$ International Conference on Advanced Research in

Table 4: Effects from the Cohort Positions of Foregoing 3 Surveyed Years

\begin{tabular}{|c|c|c|c|c|c|c|c|}
\hline Years & 1997 & 2000 & 2004 & 2006 & 2009 & 2011 & 2015 \\
\hline 1989 & $.26 * * *(0$. & & & & & & \\
\hline \multirow[t]{2}{*}{1991} & $0.30^{* * *}$ & $0.21^{* * *}$ & & & & & \\
\hline & $(0.02)$ & $(0.02)$ & & & & & \\
\hline \multirow[t]{2}{*}{1993} & $0.38^{* * *}$ & $0.29 * * *$ & $0.20 * * *$ & & & & \\
\hline & $(0.02)$ & $(0.02)$ & $(0.02)$ & & & & \\
\hline \multirow[t]{2}{*}{1997} & & $0.43^{* * *}$ & $0.28^{* * *}$ & $0.25^{* * *}$ & & & \\
\hline & & $(0.02)$ & $(0.02)$ & $(0.02)$ & & & \\
\hline \multirow[t]{2}{*}{2000} & & & $0.44^{* * * *}$ & $0.28^{* * * *}$ & $0.33^{* * *}$ & & \\
\hline & & & $(0.02)$ & $(0.02)$ & $(0.02)$ & & \\
\hline \multirow[t]{2}{*}{2004} & & & & $0.43 * * *$ & $0.36^{* * *}$ & $0.29 * * *$ & \\
\hline & & & & $(0.02)$ & $(0.03)$ & $(0.03)$ & \\
\hline \multirow[t]{2}{*}{2006} & & & & & $0.30^{* * * *}$ & $0.26^{* * *}$ & $0.28^{* * *}$ \\
\hline & & & & & $(0.02)$ & $(0.03)$ & $(0.03)$ \\
\hline \multirow[t]{2}{*}{2009} & & & & & & $0.43 * * *$ & $0.33^{* *}=$ \\
\hline & & & & & & $(0.03)$ & $(0.04)$ \\
\hline 2011 & & & & & & & $30 * * *(0$ \\
\hline
\end{tabular}

$\begin{array}{llllllll}\text { Observations } & 3,103 & 2,763 & 1,766 & 1,769 & 1,539 & 1,362 & 915\end{array}$

$\begin{array}{llllllll}\text { R-squared } & 0.78 & 0.78 & 0.77 & 0.82 & 0.84 & 0.83 & 0.82\end{array}$

Standard errors in parentheses

$* * * \mathrm{p}<0.01, * * \mathrm{p}<0.05, * \mathrm{p}<0.1$ 


\section{icallalyme}

$2^{\text {nd }}$ International Conference on Advanced Research in

MUNICH, GERMANY

BUSINESS, MANAGEMENT \& ECONOMICS

6 - 8 DECEMBER, 2019

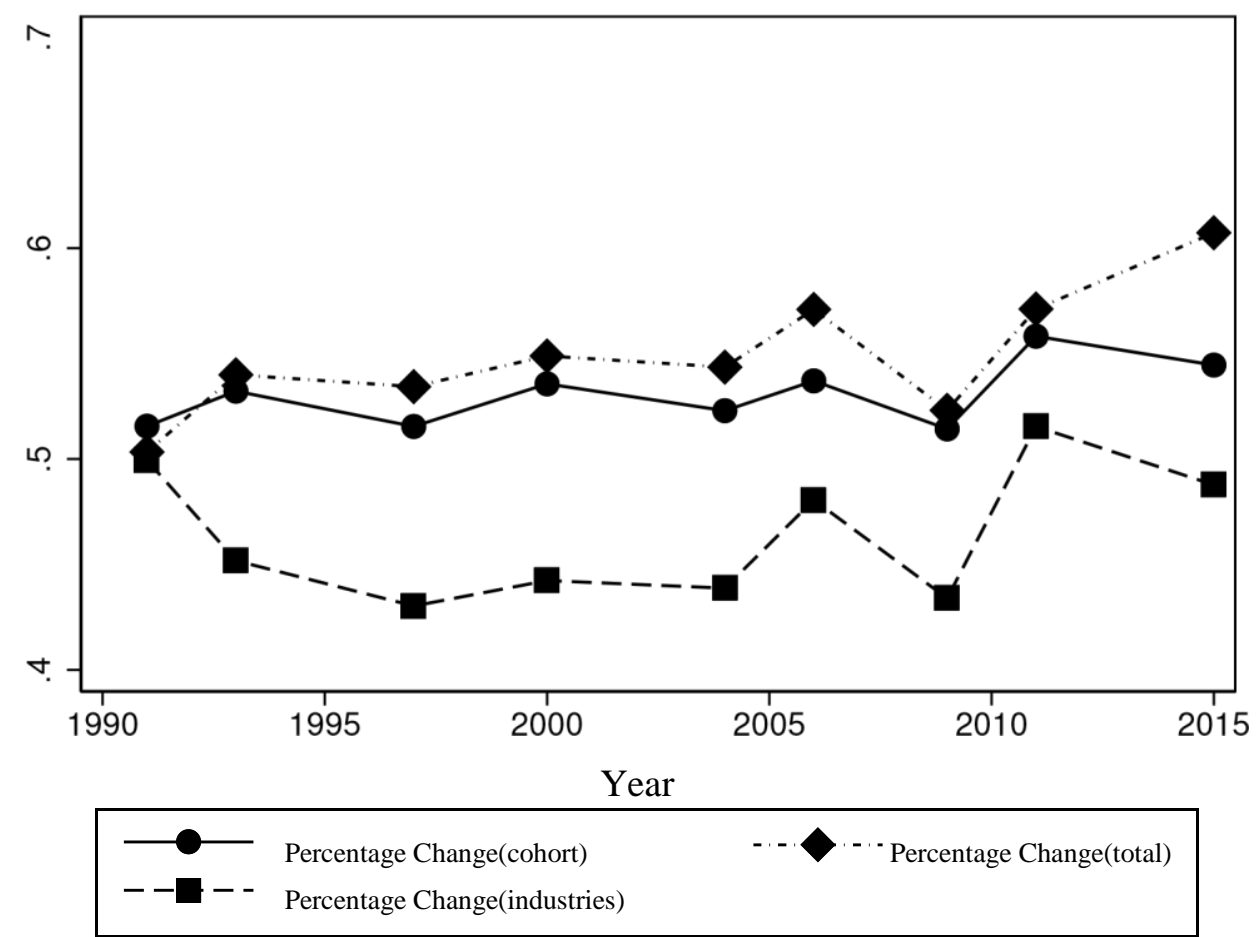

Figure 1: Poor to Poor

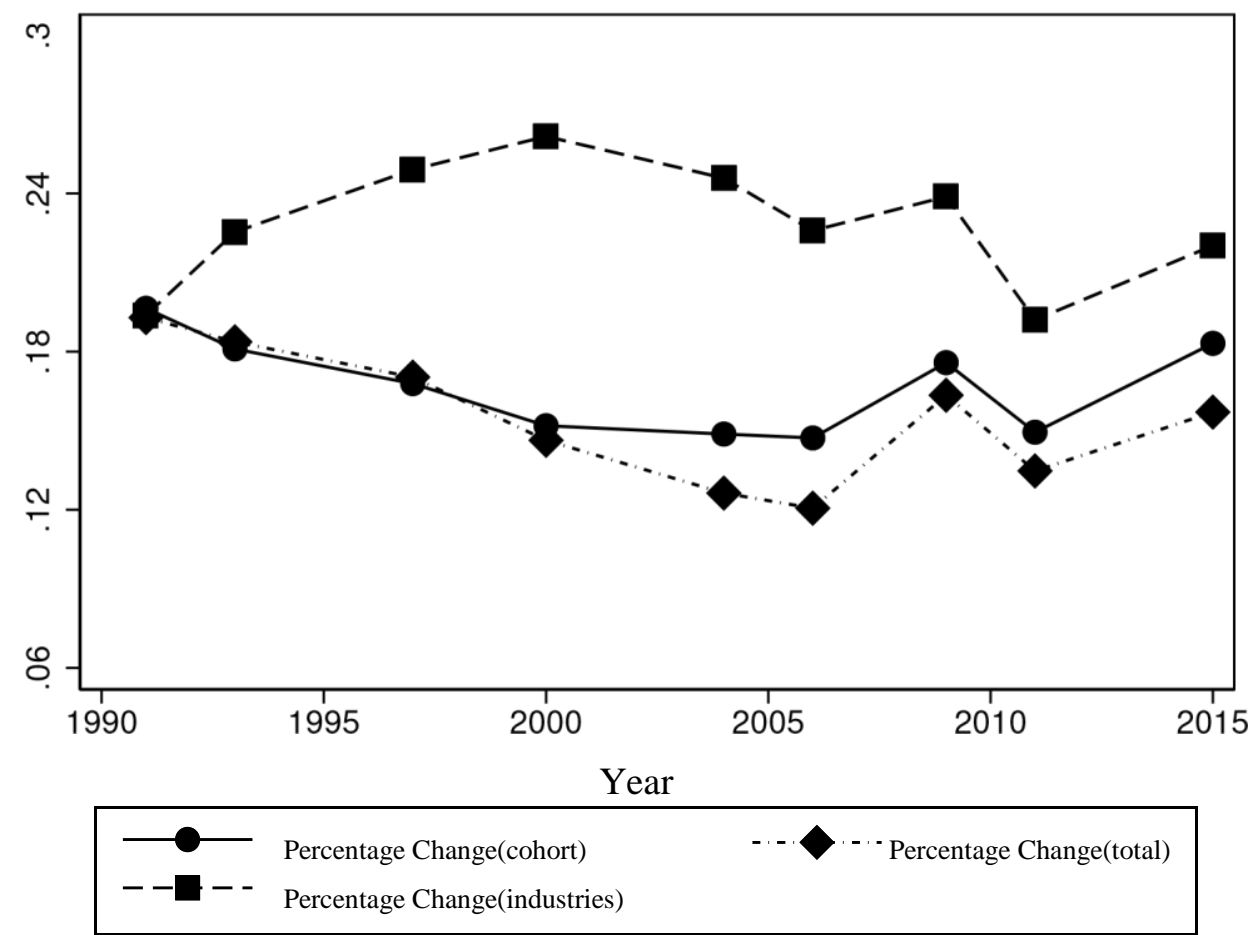

Figure 2: Poor to Rich 


\section{ical|lingme}

$2^{\text {nd }}$ International Conference on Advanced Research in

MUNICH, GERMANY

BUSINESS, MANAGEMENT \& ECONOMICS

6 - 8 DECEMBER, 2019

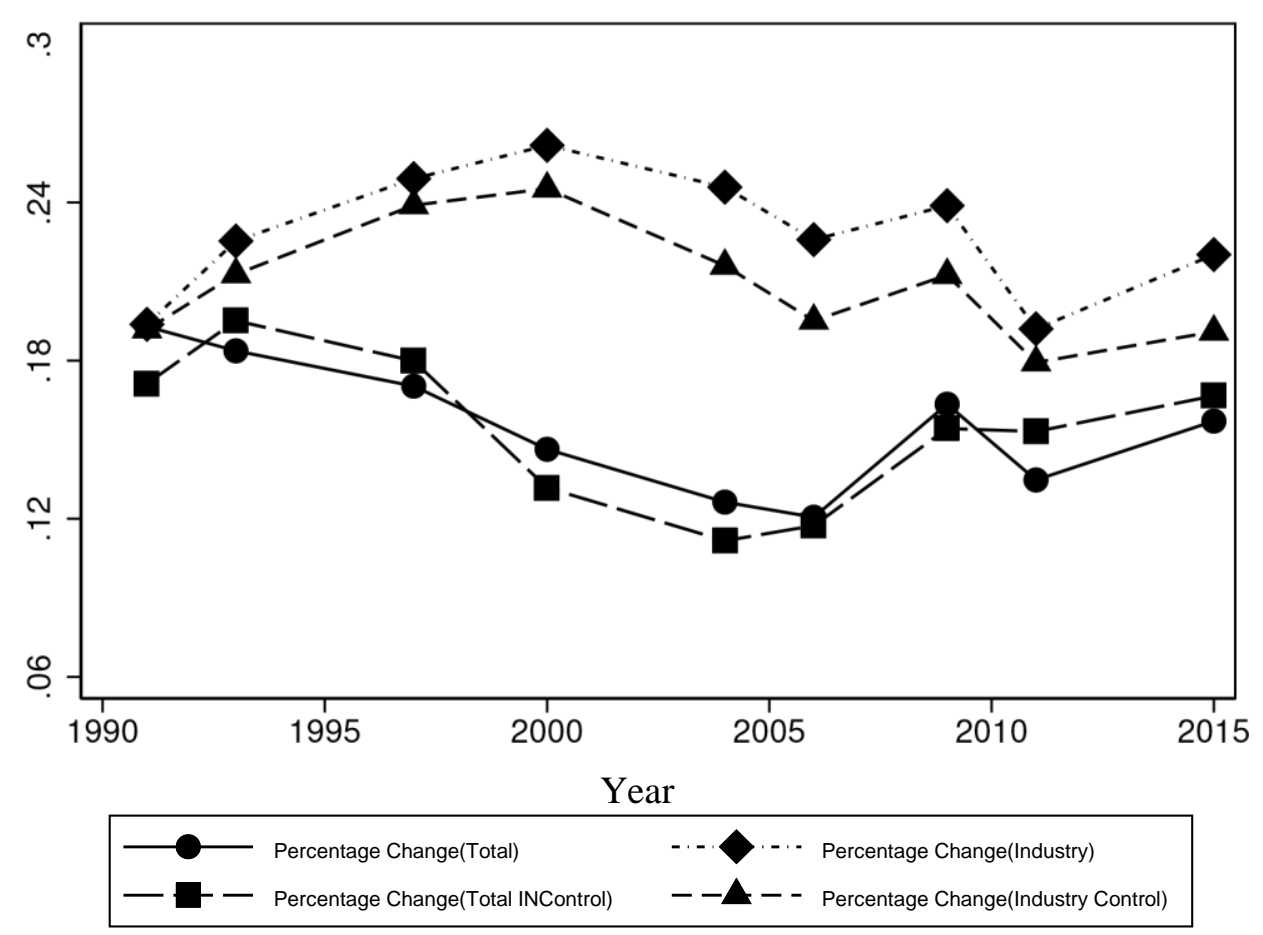

Figure 3: Poor to Rich (Industry Control)

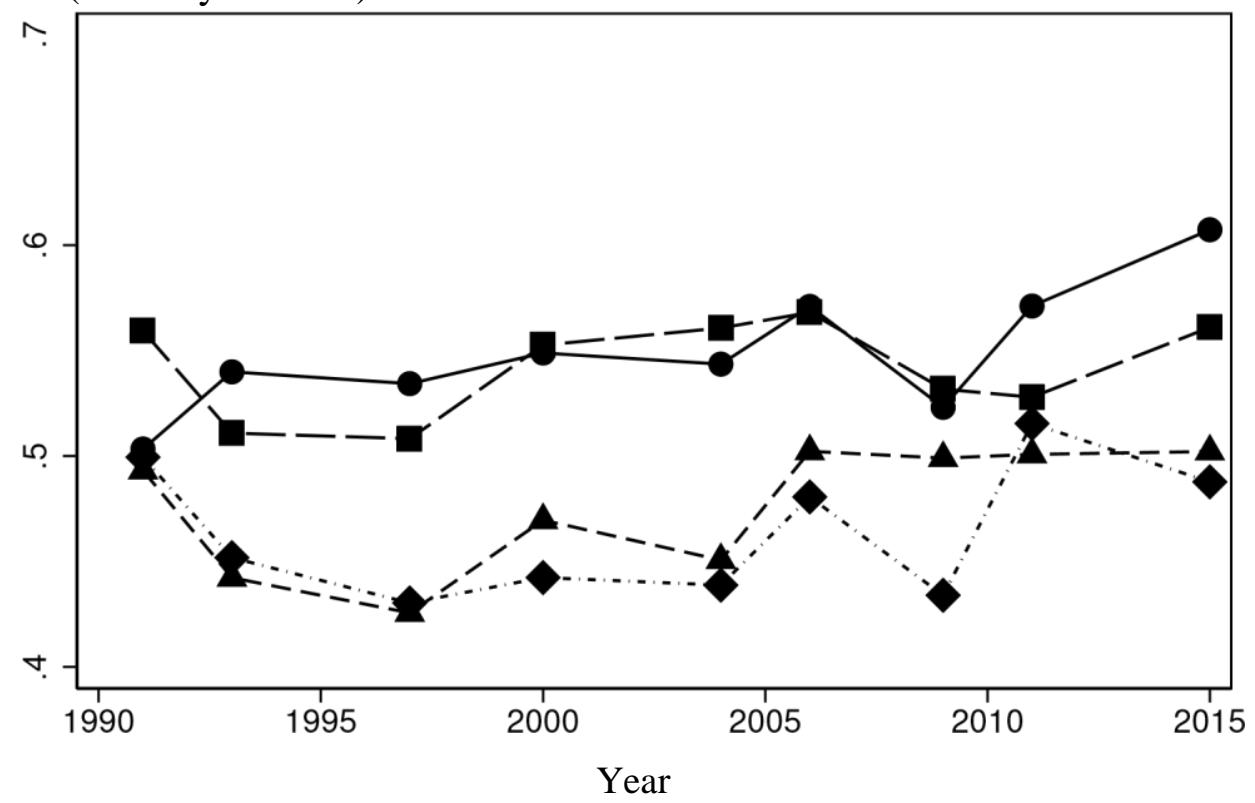




\section{icallalyme}

$2^{\text {nd }}$ International Conference on Advanced Research in

MUNICH, GERMANY BUSINESS, MANAGEMENT \& ECONOMICS

$\begin{array}{llll} & \text { Percentage Change(Total) }\end{array}$

Figure 4: Poor to Poor (Industry Control)

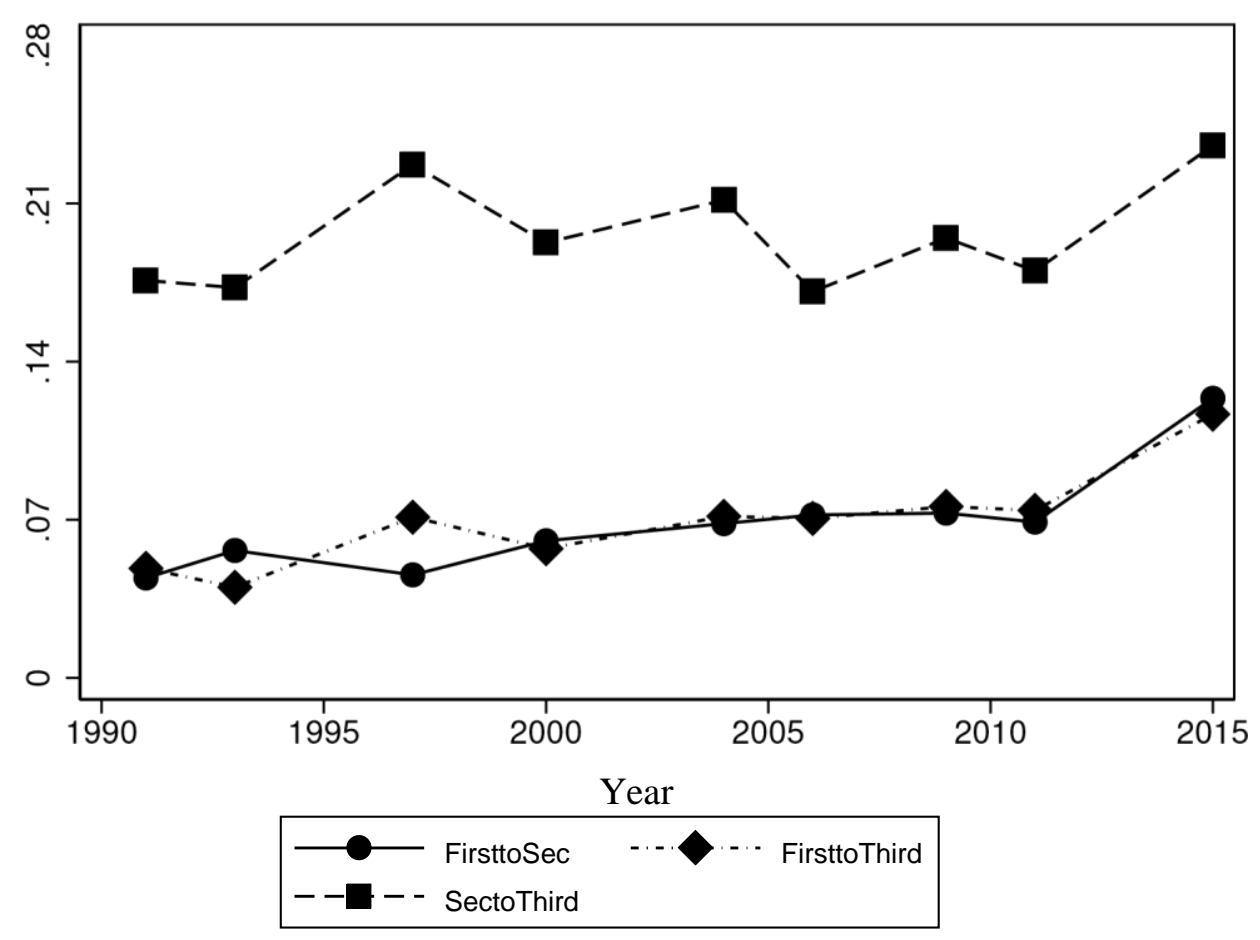

Figure 5: Industry Forward Ratio 


\section{icalinme}

$2^{\text {nd }}$ International Conference on Advanced Research in

MUNICH, GERMANY

BUSINESS, MANAGEMENT \& ECONOMICS

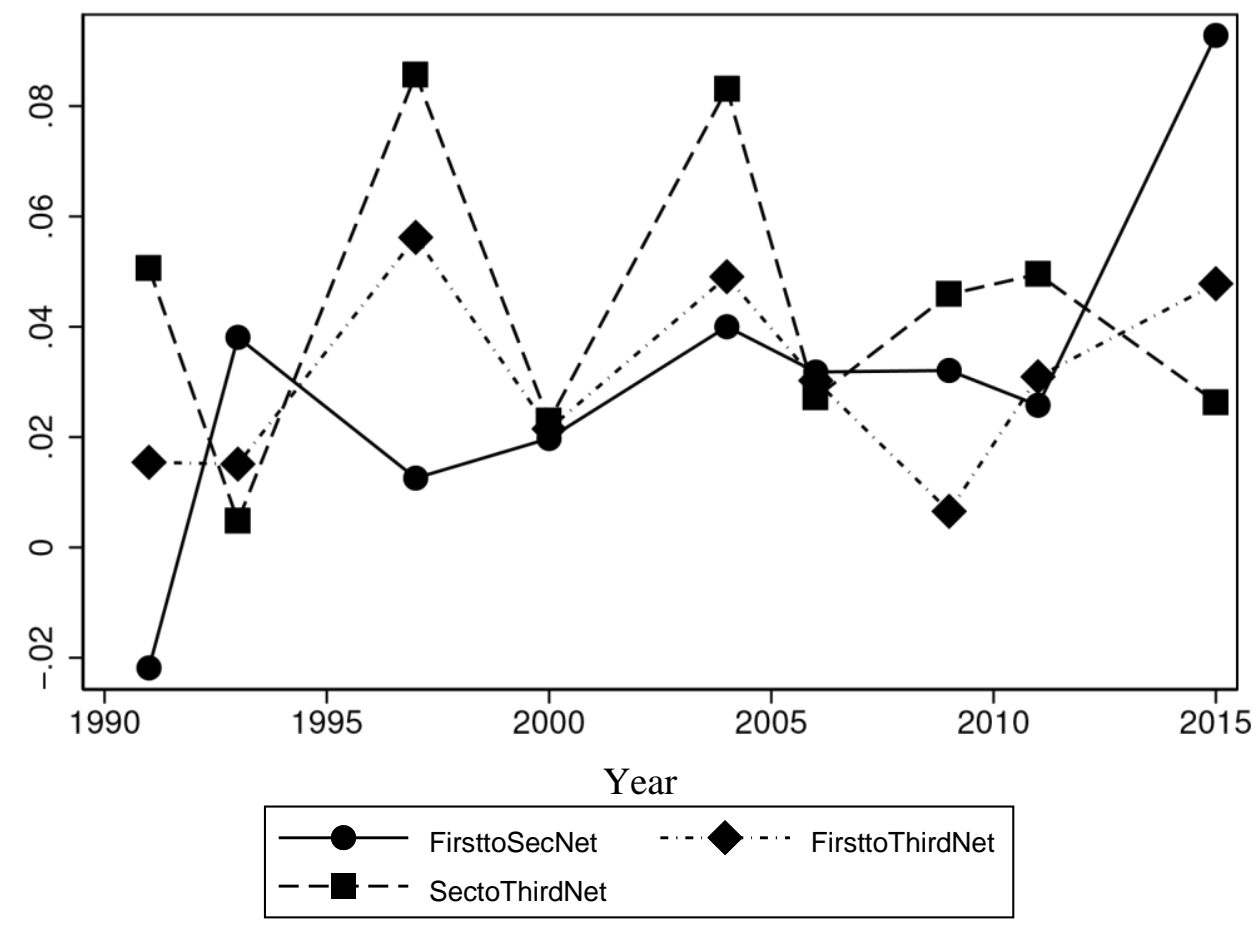

Figure 6: Industry Net Change Ratio

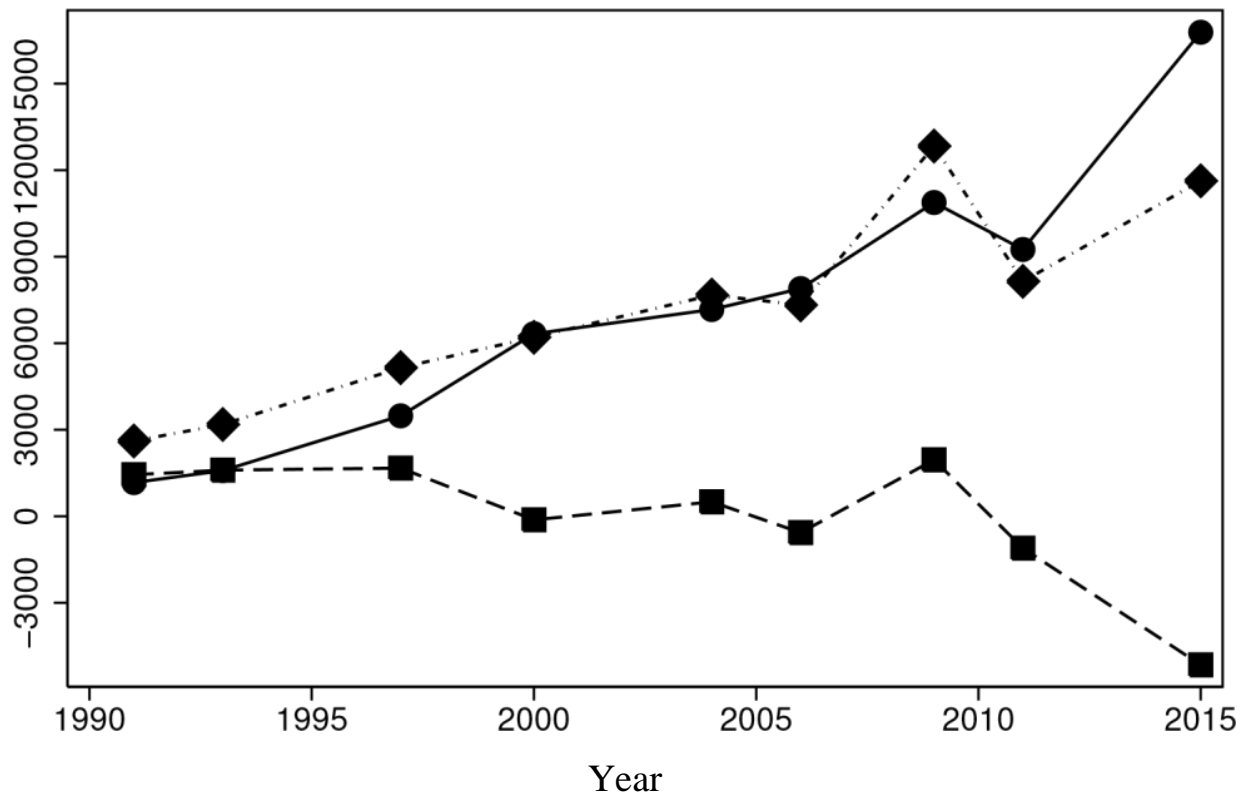




\section{icalinme}

$2^{\text {nd }}$ International Conference on Advanced Research in

MUNICH, GERMANY

BUSINESS, MANAGEMENT \& ECONOMICS

\begin{tabular}{lllll}
$\longrightarrow$ & INCFirsttoSec & $\cdots$ & $\cdots$ & INCFirsttoThird \\
$--6--$ & INCSectoThird & & \\
\hline
\end{tabular}

Figure 7: Relative Income Change

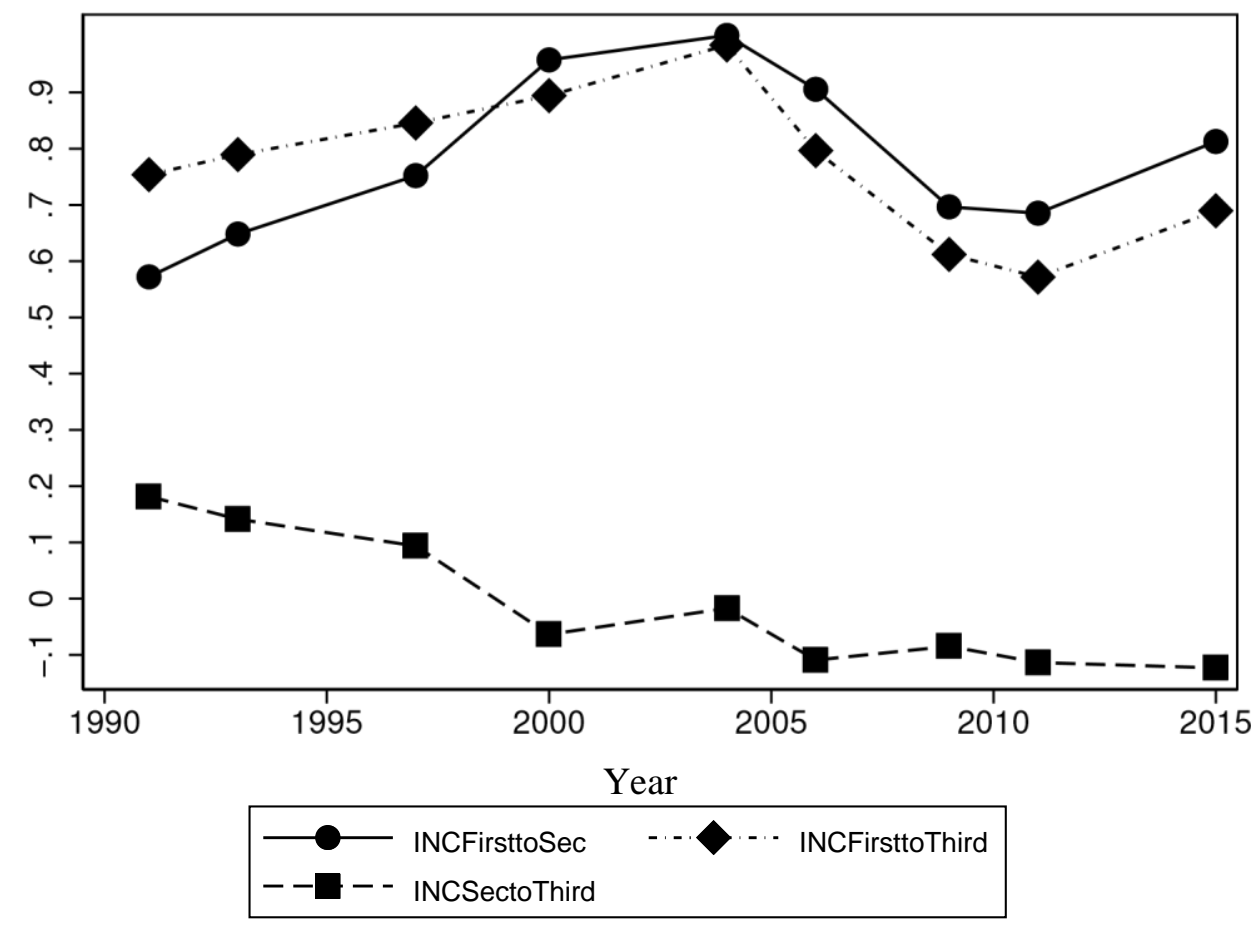




\section{icalinme}

$2^{\text {nd }}$ International Conference on Advanced Research in

MUNICH, GERMANY

BUSINESS, MANAGEMENT \& ECONOMICS

igure 8: Relative Income Change(Percentage)

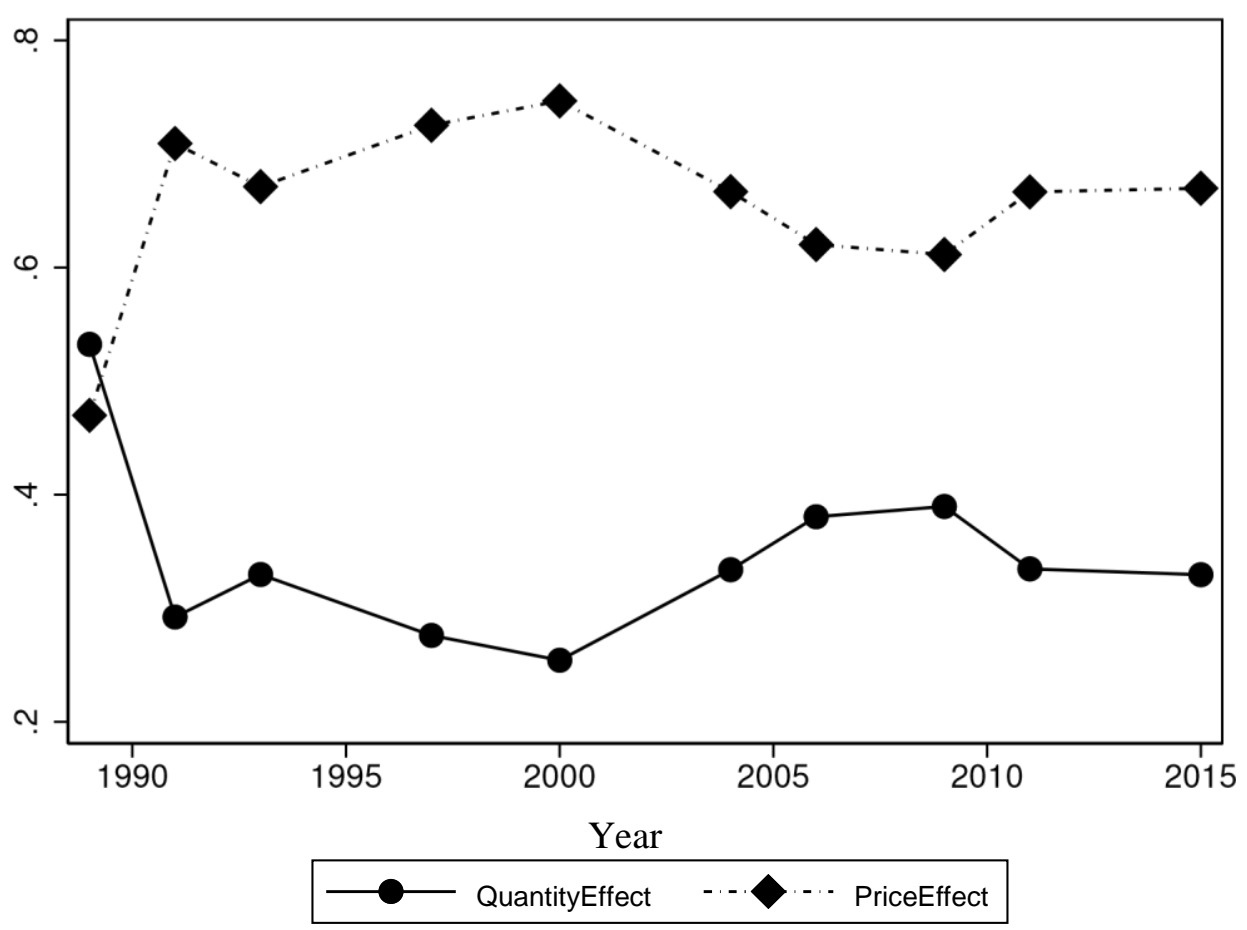




\section{icalinme}

$2^{\text {nd }}$ International Conference on Advanced Research in

MUNICH, GERMANY

BUSINESS, MANAGEMENT \& ECONOMICS

Figure 9: JMP Decomposition(First to Second Industry)

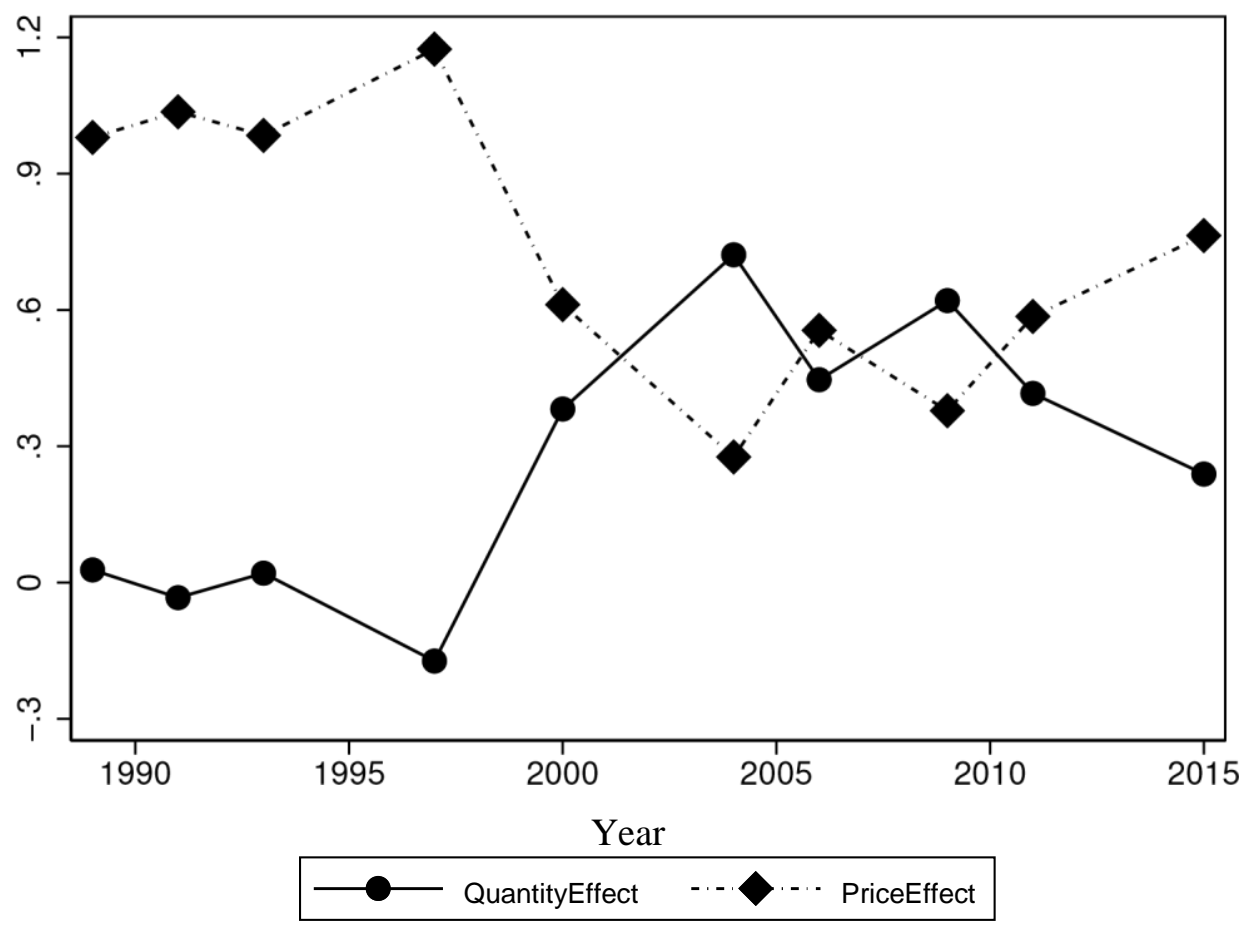

Figure 10: JMP Decomposition(Second to Third Industry)

Appendix

Table A1: Other Variables Summary

\begin{tabular}{cccccc}
\hline Variable & Mean & Std. Dev. & Min. & Max. & N \\
\hline Highest Educational Level & 8.55 & 4.29 & 0 & 18 & 20083 \\
Age & 42.89 & 14.69 & 18 & 94 & 21868 \\
Ethnicity Han & 0.88 & 0.32 & 0 & 1 & 20970 \\
Female & 0.50 & 0.50 & 0 & 1 & 21874 \\
\hline
\end{tabular}




\section{icalielme}

$2^{\text {nd }}$ International Conference on Advanced Research in

MUNICH, GERMANY

BUSINESS, MANAGEMENT \& ECONOMICS

Table A2: Income Summary without Winsorisation

\begin{tabular}{cccccc}
\hline Year & Mean & Std. Dev. & Min. & Max. & N \\
\hline 1989 & 4790.62 & 5971.32 & 5.37 & 129413.38 & 8099 \\
1991 & 4384.90 & 4294.73 & 2.22 & 83733.05 & 8047 \\
1993 & 5172.61 & 6320.39 & 1.39 & 213681.61 & 7310 \\
1997 & 7527.41 & 7902.82 & 9.12 & 135830.47 & 7538 \\
2000 & 9391.98 & 11309.12 & 4.85 & 199636.97 & 7662 \\
2004 & 11359.55 & 14053.72 & 9.20 & 219502.33 & 5139 \\
2006 & 14657.88 & 21762.56 & 1.61 & 434784.69 & 4938 \\
2009 & 20747.42 & 33946.00 & 7.50 & 800200.50 & 5349 \\
2011 & 26844.09 & 33716.87 & 10.54 & 632639.06 & 6906 \\
2015 & 45269.53 & 103290.33 & 40.00 & 4800000.00 & 5720 \\
\hline
\end{tabular}

Table A3: Income Summary with 5 Percentage Winsorisation

\begin{tabular}{cccccc}
\hline Year & Mean & Std. Dev. & Min. & Max. & N \\
\hline 1989 & 4301.07 & 3249.63 & 429.29 & 13050.38 & 8099 \\
1991 & 4087.92 & 2879.65 & 485.27 & 11376.91 & 8047 \\
1993 & 4708.36 & 3735.76 & 399.47 & 14198.62 & 7310 \\
1997 & 7034.29 & 5404.84 & 672.29 & 20525.49 & 7538 \\
2000 & 8477.37 & 6439.91 & 696.46 & 23355.38 & 7662 \\
2004 & 10321.18 & 8549.73 & 652.99 & 31096.16 & 5139 \\
2006 & 12820.22 & 10497.84 & 852.77 & 38960.72 & 4938 \\
2009 & 17688.66 & 13572.44 & 1718.49 & 52098.29 & 5349 \\
2011 & 23835.03 & 17945.79 & 2394.99 & 69590.30 & 6906 \\
2015 & 36009.03 & 25198.23 & 3429.46 & 102000.00 & 5720 \\
\hline
\end{tabular}




\section{icallibme}

$2^{\text {nd }}$ International Conference on Advanced Research in

MUNICH, GERMANY

BUSINESS, MANAGEMENT \& ECONOMICS

6 - 8 DECEMBER, 2019

Table A4: Cohort Position Factors

\begin{tabular}{|c|c|c|c|c|c|c|c|c|c|c|}
\hline Education & $\begin{array}{c}1.03 * * * \\
(0.08)\end{array}$ & $\begin{array}{c}1.34 * * * \\
(0.08)\end{array}$ & $\begin{array}{c}1.27 * * * \\
(0.08)\end{array}$ & $\begin{array}{r}1.54 * *: \\
(0.08)\end{array}$ & $\begin{array}{r}2.08 * *: \\
(0.08)\end{array}$ & $\begin{array}{r}2.36^{* *:} \\
(0.09)\end{array}$ & $\begin{array}{c}2.40 * * * \\
(0.09)\end{array}$ & $\begin{array}{c}2.25 * * * \\
(0.09)\end{array}$ & $\begin{array}{c}1.87 * * * \\
(0.09)\end{array}$ & $\begin{array}{c}2.00 * * * \\
(0.11)\end{array}$ \\
\hline \multirow[t]{2}{*}{ Female } & $-3.61 * * *$ & $-4.02 * * *$ & $-2.77 * * *$ & $-5.10 * *$ & $-5.04 * *$ & $-4.62 * *$ & $-8.41 * * *$ & $-5.83 * * *$ & $-6.73 * * *$ & $-8.88 * * *$ \\
\hline & $(0.67)$ & $(0.64)$ & $(0.68)$ & $(0.67)$ & $(0.63)$ & $(0.74)$ & $(0.76)$ & $(0.74)$ & $(0.75)$ & $(0.82)$ \\
\hline \multirow[t]{2}{*}{ Liaoning } & $42.72 * * *$ & $46.08 * * *$ & $44.65^{* * * y}$ & & $37.66^{* *}$ & $32.92 * *$ & $35.74 * * *$ & $32.04 * * *$ & $37.32 * * *$ & $31.45^{* * *}$ \\
\hline & (1.34) & (1.28) & $(1.36)$ & & $(1.31)$ & (1.50) & $(1.51)$ & (1.49) & $(1.50)$ & (1.63) \\
\hline \multirow[t]{2}{*}{ Jiangsu } & $53.81 * * *$ & $47.75 * * *$ & 50.18 **y & $50.70 * *$ & $45.16 * *$ & $47.35 * *$ & $45.10 * * *$ & $44.44 * * *$ & $50.85 * * *$ & $47.65 * * *$ \\
\hline & (1.13) & (1.11) & (1.16) & (1.15) & (1.12) & (1.29) & (1.31) & (1.35) & (1.37) & (1.62) \\
\hline \multirow[t]{2}{*}{ Shandong } & $49.74 * * *$ & $45.97 * * *$ & $47.04 * *$ * & $45.53 * *$ & $43.46^{* *}$ & $32.87 * *$ & $34.02 * * *$ & $32.17 * * *$ & $34.76 * * *$ & $33.31 * * *$ \\
\hline & (1.21) & (1.17) & $(1.25)$ & (1.29) & (1.31) & (1.44) & (1.53) & (1.44) & (1.49) & (1.80) \\
\hline \multirow[t]{2}{*}{ Henan } & $40.19 * * *$ & $35.78 * * *$ & $30.67 * * y$ & $32.69 * *$ & $26.05 * *$ & $25.45 * *$ & $24.60 * * *$ & $23.71 * * *$ & $25.52 * * *$ & $25.55 * * *$ \\
\hline & (1.16) & (1.08) & (1.16) & (1.13) & (1.19) & (1.44) & (1.55) & (1.44) & (1.45) & (1.81) \\
\hline \multirow[t]{2}{*}{ Hubei } & $41.85 * * *$ & $46.92 * * *$ & 37.78 **y & $40.04 * *$ & $32.25 * *$ & $30.43 * *$ & $34.49 * * *$ & $35.93 * * *$ & $41.67 * * *$ & $39.22 * * *$ \\
\hline & (1.13) & (1.10) & (1.17) & (1.17) & (1.16) & (1.38) & (1.44) & $(1.41)$ & (1.45) & (1.54) \\
\hline \multirow[t]{2}{*}{ Hunan } & $51.83 * * *$ & $48.02 * * *$ & $49.48 * * \cdots$ & $51.12 * *$ & $45.26 * *$ & $35.38 * *$ & $36.20 * * *$ & $40.27 * * *$ & $41.06 * * *$ & $39.87 * * *$ \\
\hline & $(1.21)$ & (1.19) & $(1.28)$ & $(1.33)$ & $(1.34)$ & (1.59) & $(1.50)$ & $(1.52)$ & (1.64) & $(1.81)$ \\
\hline \multirow[t]{2}{*}{ Guangxi } & $43.53 * * *$ & $39.10 * * *$ & $44.21 * * \cdots$ & $40.92 * *$ & $36.74 * *$ & $27.83 * *$ & $27.28 * * *$ & $27.01 * * *$ & $28.45 * * *$ & $24.88 * * *$ \\
\hline & (1.11) & $(1.08)$ & (1.13) & (1.13) & (1.11) & $(1.33)$ & $(1.37)$ & $(1.35)$ & $(1.37)$ & $(1.56)$ \\
\hline \multirow[t]{2}{*}{ Guizhou } & $38.09 * * *$ & $36.05 * * *$ & $38.82 * * *$ & $34.18 * *$ & $31.88 * *$ & $28.71 * *$ & $32.92 * * *$ & $36.41 * * *$ & $40.67 * * *$ & $37.72 * * *$ \\
\hline & $(1.05)$ & $(1.01)$ & (1.06) & (1.06) & (1.04) & $(1.20)$ & $(1.25)$ & (1.33) & (1.38) & $(1.56)$ \\
\hline \multirow[t]{2}{*}{ Heilongjiang } & & & & $36.55 * *$ & $30.06 * *$ & $39.26 * *$ & $34.89 * * *$ & $34.21 * * *$ & $37.43 * * *$ & $31.61 * * *$ \\
\hline & & & & $(1.28)$ & $(1.24)$ & $(1.45)$ & $(1.43)$ & $(1.41)$ & $(1.42)$ & $(1.73)$ \\
\hline
\end{tabular}




\section{icalibme}

$2^{\text {nd }}$ International Conference on Advanced Research in

MUNICH, GERMANY

BUSINESS, MANAGEMENT \& ECONOMICS

\begin{tabular}{|c|c|c|c|c|c|c|c|}
\hline Observations & 7,290 & 7,823 & 7,015 & 6,966 & 7,273 & 5,125 & 4,926 \\
\hline R-squared & 0.77 & 0.77 & 0.77 & 0.78 & 0.79 & 0.80 & 0.80 \\
\hline
\end{tabular}

Table A5: Correlations of Position within Cohorts

\begin{tabular}{|c|c|c|c|c|c|c|c|c|c|c|}
\hline Year & 2015 & 2011 & 2009 & 2006 & 2004 & 2000 & 1997 & 1993 & 1991 & 1989 \\
\hline
\end{tabular}

Nb. Obs. 2011

\begin{tabular}{|c|c|c|c|c|c|c|c|c|c|}
\hline & 0.50 & 1.00 & & & & & & & \\
\hline Nb. Obs. & 2949 & & & & & & & & \\
\hline 2009 & 0.40 & 0.50 & 1.00 & & & & & & \\
\hline Nb. Obs. & 1872 & 3382 & & & & & & & \\
\hline 2006 & 0.37 & 0.40 & 0.46 & 1.00 & & & & & \\
\hline Nb. Obs. & 1449 & 2438 & 2804 & & & & & & \\
\hline 2004 & 0.31 & 0.39 & 0.45 & 0.51 & 1.00 & & & & \\
\hline Nb. Obs. & 1402 & 2312 & 2588 & 3023 & & & & & \\
\hline 2000 & 0.29 & 0.29 & 0.37 & 0.40 & 0.43 & 1.00 & & & \\
\hline Nb. Obs. & 1616 & 2679 & 2990 & 3237 & 3714 & & & & \\
\hline 1997 & 0.15 & 0.24 & 0.31 & 0.33 & 0.35 & 0.42 & 1.00 & & \\
\hline Nb. Obs. & 1312 & 2284 & 2585 & 2712 & 3058 & 5114 & & & \\
\hline 1993 & 0.07 & 0.20 & 0.26 & 0.26 & 0.25 & 0.33 & 0.38 & 1.00 & \\
\hline Nb. Obs. & 1142 & 1840 & 2079 & 2158 & 2407 & 3895 & 4303 & & \\
\hline 1991 & 0.13 & 0.19 & 0.20 & 0.26 & 0.24 & 0.27 & 0.32 & 0.39 & 1.00 \\
\hline
\end{tabular}




\section{icalielme}

$2^{\text {nd }}$ International Conference on Advanced Research in

MUNICH, GERMANY

BUSINESS, MANAGEMENT \& ECONOMICS

$\begin{array}{ccccccccccc}\text { Nb. Obs. } & 1097 & 1844 & 2053 & 2177 & 2390 & 3826 & 4160 & 6182 & \\ 1989 & 0.09 & 0.11 & 0.14 & 0.21 & 0.19 & 0.24 & 0.26 & 0.30 & 0.36 & 1.00 \\ \text { Nb. Obs. } & 1031 & 1734 & 1884 & 2071 & 2235 & 3502 & 3755 & 5515 & 6458 & \end{array}$

Table A6: Correlations of Position within All Observations

\begin{tabular}{lllllllllll}
\hline Year & 2015 & 2011 & 2009 & 2006 & 2004 & 2000 & 1997 & 1993 & 1991 & 1989 \\
\hline 2015 & 1.00 & & & & &
\end{tabular}

Nb. Obs. 2011

\begin{tabular}{|c|c|c|c|c|c|c|c|c|c|}
\hline & 0.54 & 1.00 & & & & & & & \\
\hline Nb. Obs. & 2949 & & & & & & & & \\
\hline 2009 & 0.41 & 0.53 & 1.00 & & & & & & \\
\hline Nb. Obs. & 1872 & 3382 & & & & & & & \\
\hline 2006 & 0.42 & 0.45 & 0.50 & 1.00 & & & & & \\
\hline Nb. Obs. & 1449 & 2438 & 2804 & & & & & & \\
\hline 2004 & 0.32 & 0.43 & 0.49 & 0.56 & 1.00 & & & & \\
\hline Nb. Obs. & 1402 & 2312 & 2588 & 3023 & & & & & \\
\hline 2000 & 0.30 & 0.33 & 0.40 & 0.43 & 0.47 & 1.00 & & & \\
\hline Nb. Obs. & 1616 & 2679 & 2990 & 3237 & 3714 & & & & \\
\hline 1997 & 0.14 & 0.26 & 0.33 & 0.36 & 0.38 & 0.45 & 1.00 & & \\
\hline Nb. Obs. & 1312 & 2284 & 2585 & 2712 & 3058 & 5114 & & & \\
\hline 1993 & 0.07 & 0.20 & 0.25 & 0.26 & 0.26 & 0.34 & 0.41 & 1.00 & \\
\hline Nb. Obs. & 1142 & 1840 & 2079 & 2158 & 2407 & 3895 & 4303 & & \\
\hline 1991 & 0.13 & 0.18 & 0.18 & 0.25 & 0.24 & 0.29 & 0.36 & 0.43 & 1.00 \\
\hline
\end{tabular}




\section{icalinme}

$2^{\text {nd }}$ International Conference on Advanced Research in MUNICH, GERMANY BUSINESS, MANAGEMENT \& ECONOMICS

Nb. Obs.

1097

$1844 \quad 2053$

2177

$2390 \quad 3826$

4160

6182

1989

0.07

0.09

0.13

0.20

0.19

0.23

0.28

0.33

0.39

1.00

Nb. Obs.

1031

1734

1884

2071

2235

3502

3755

$5515 \quad 6458$

Table A7: Effects from the Cohort Positions of Foregoing 2 Surveyed Years

\begin{tabular}{|c|c|c|c|c|c|c|c|c|}
\hline Year & 1993 & 1997 & 2000 & 2004 & 2006 & 2009 & 2011 & 2015 \\
\hline 1989 & $0.38 * * *(0.01)$ & & & & & & & \\
\hline \multirow[t]{2}{*}{1991} & $0.55^{* * *}$ & $0.41 * * *$ & & & & & & \\
\hline & $(0.01)$ & $(0.02)$ & & & & & & \\
\hline \multirow[t]{2}{*}{1993} & & $0.50 * * *$ & $0.39 * * *$ & & & & & \\
\hline & & $(0.02)$ & $(0.02)$ & & & & & \\
\hline \multirow[t]{2}{*}{1997} & & & $0.53 * * *$ & $0.41 * * *$ & & & & \\
\hline & & & $(0.02)$ & $(0.02)$ & & & & \\
\hline \multirow[t]{2}{*}{2000} & & & & $0.53 * * *$ & $0.39 * * *$ & & & \\
\hline & & & & $(0.02)$ & $(0.02)$ & & & \\
\hline \multirow[t]{2}{*}{2004} & & & & & $0.55 * * *$ & $0.50 * * *$ & & \\
\hline & & & & & $(0.02)$ & $(0.02)$ & & \\
\hline \multirow[t]{2}{*}{2006} & & & & & & $0.46^{* * * *}$ & $0.39 * * *$ & \\
\hline & & & & & & $(0.02)$ & $(0.02)$ & \\
\hline \multirow[t]{2}{*}{2009} & & & & & & & $0.58 * * *$ & $0.45^{* * *}$ \\
\hline & & & & & & & $(0.02)$ & $(0.03)$ \\
\hline
\end{tabular}




\section{icalinme}

$2^{\text {nd }}$ International Conference on Advanced Research in

MUNICH, GERMANY

BUSINESS, MANAGEMENT \& ECONOMICS

6 - 8 DECEMBER, 2019

2011

$0.41 * * *(0.03$

\begin{tabular}{|c|c|c|c|c|c|}
\hline Observation & 4,907 & 3,659 & 3,079 & 2,712 & 2,351 \\
\hline R-squared & 0.78 & 0.75 & 0.77 & 0.78 & 0.81 \\
\hline
\end{tabular}

\section{References}

Bian, Yanjie. 2002. "Chinese social stratification and social mobility." Annual review of sociology, 28(1): 91-116.

Brandt, Loren, and Xiaodong Zhu. 2000. "Redistribution in a decentralized economy: growth and inflation in China under reform.” Journal of Political Economy, 108(2): 422-439.

Chen, Jian, and Belton M Fleisher. 1996. "Regional income inequality and economic growth in China." Journal of comparative economics, 22(2): 141-164.

Chen, Yi, and Frank A Cowell. 2017. "Mobility in China." Review of Income and Wealth, 63(2): 203-218.

Fan, C Cindy, and Mingjie Sun. 2008. "Regional inequality in China, 1978-2006." Eurasian geography and Economics, 49(1): 1-18.

Jerrim, John, and Lindsey Macmillan. 2015. "Income inequality, intergenerational mobility, and the Great Gatsby Curve: Is education the key?” Social Forces, 94(2): 505-533.

Juhn, Chinhui, Kevin M Murphy, and Brooks Pierce. 1993. "Wage inequality and the rise in returns to skill." Journal of political Economy, 101(3): 410-442.

Kanbur, Ravi, and Xiaobo Zhang. 1999. "Which regional inequality? The evolution of rural-urban and inland-coastal inequality in China from 1983 to 1995." Journal of comparative economics, 27(4): 686-701.

Nee, Victor. 1996. "The emergence of a market society: Changing mechanisms of stratification in China." American journal of sociology, 101(4): 908-949.

Sicular, Terry, Yue Ximing, Bjorn Gustafsson, and Li Shi." 2007. "The urban-rural income gap and inequality in China." Review of Income and Wealth, 53(1): 93-126. 


\section{icalinme}

$2^{\text {nd }}$ International Conference on Advanced Research in

Wisman, Jon D. 2013. "Wage stagnation, rising inequality and the financial crisis of 2008." Cambridge Journal of Economics, 37(4): 921-945.

$\mathrm{Wu}$, Xiaogang, and Donald J Treiman. 2004. "The household registration system and social stratification in China: 1955-1996." Demography, 41(2): 363-384.

Xie, Yu, and Xiang Zhou. 2014. "Income inequality in today's China." Proceedings of the National Academy of Sciences, 111(19): 6928-6933.

Zhang, Junsen, Yaohui Zhao, Albert Park, and Xiaoqing Song. 2005. "Economic returns to schooling in urban China, 1988 to 2001." Journal of comparative economics, 33(4): 730-752.

Zhou, Xiang, and Yu Xie. 2017. "Market transition, industrialization, and social mobility trends in postrevolution China." Industrialization, and Social Mobility Trends in Post-Revolution China (June 2017). 